\title{
Goal Setting Interventions: Implications for Participants on the Autism Spectrum
}

\author{
Monica E. Carr • Dennis W. Moore • Angelika Anderson
}

Received: 13 January 2014 / Accepted: 23 May 2014 / Published online: 3 June 2014

(C) Springer Science+Business Media New York 2014

\begin{abstract}
Single-case research design studies that included a goal setting component in interventions for a broad array of participants engaged in a learner role were reviewed. A systematic search of the empirical literature identified 38 studies that met the inclusion criteria. These studies were evaluated in terms of participant characteristics, who set the goals (self or other), how goals were incorporated into interventions, type of behavior change goal setting was applied to and whether maintenance and generalization of intervention effects was assessed. Results highlight the potential benefits of including a self-set goal component in interventions aimed at assisting participants across the autism spectrum to achieve independent functioning. An agenda is proposed for future research exploring goal setting for this population.
\end{abstract}

Keywords Autism spectrum disorder · Goal setting · Self-management $\cdot$ Systematic review

This study was completed in partial fulfilment of the requirements for a $\mathrm{PhD}$ for the first author.

\section{E. Carr ( $\bowtie)$}

Faculty of Education, Monash University, Building 6, Clayton

Campus, Clayton, Victoria 3800, Australia

e-mail: mebar4@student.monash.edu

D. W. Moore $\cdot$ A. Anderson

Krongold Centre, Faculty of Education, Monash University, Building 6, Clayton Campus, Clayton, Victoria 3800, Australia

D. W. Moore

e-mail: Dennis.Moore@monash.edu

A. Anderson

e-mail: Angelika.Anderson@monash.edu

\section{Introduction}

Goals have been defined as the object or aim of an action that an individual is trying to accomplish, and it is generally understood that goal attainment involves meeting a specific standard of task proficiency within an acceptable time frame (Locke et al. 1981). Several published reviews have reported that goal setting and goal attainment are important components of self-determination for students with various developmental or learning disabilities (Algozzine et al. 2001; Fowler et al. 2007; Konrad et al. 2007; Palmer and Wehmeyer 2003). Self-determination has been identified by the US Department of Education as an important educational outcome for students with disabilities (Algozzine et al. 2001). The Division of Career Development and Transition (DCDT) has suggested that by the age of 14 years, students should be encouraged to the full extent of their capabilities to assume a maximum amount of responsibility in planning their futures (Halpern 1994).

The skills required to develop self-determination are derived from the classic career development literature (Super 1983) and include developing an understanding of the relationship of time to goal attainment (Field et al. 1998). Research by Palmer and Wehmeyer (2003) conducted amongst children with learning disabilities, speech impairments, giftedness and mental retardation has shown that problem solving and goal setting skills develop over time. Their findings demonstrated that children with disabilities can, with the support of teachers, set goals and work through a self-determined skill development model at as young as 5 years of age.

Copeland and Hughes (2002) conducted a review on the effects of goal setting upon task performance for individuals with a diagnosis of mental retardation (MR). The authors reported an improvement in awareness and task performance upon the introduction of goal setting, with stronger effects 
noted with more training. Self-management strategies were taught in addition to goal setting in 7 of the 17 studies reviewed and achieved positive outcomes. Similarly, Konrad et al. (2007) published a review of the effects of selfdetermination interventions on the academic skills of students with learning disabilities (LDs) and/or attention deficit/ hyperactivity disorder (ADHD). Again, stronger increases in students' productivity were achieved when goal setting was added to self-management.

The literature has indicated that goal setting skills can direct attention and effort towards relevant activities and positively affect task performance (Copeland and Hughes 2002; Konrad et al. 2007; Locke and Latham 2002). While it is evident that these skills can be learned over time, it is possible that individuals with autism spectrum disorder (ASD) are not always given adequate opportunity to acquire the necessary skills to set and attain goals or opportunity to practice them. The ability to independently set challenging, attainable and appropriate goals is an important skill for students with ASD to develop and may contribute to improved awareness, task performance, fulfilment and independent functioning.

Recently, attention has been drawn to the significant number of individuals with high-functioning autism or Asperger's syndrome who were diagnosed during the early 1990s and, as a result of early intervention and supports throughout school, are both capable and motivated to enter higher education (Pinder-Amaker 2014; VanBergeijk et al. 2008). Elsewhere, it has been reported that children with ASD may face an elevated risk for developing obesity (Curtin et al. 2014). Curtin and colleagues (2014) postulated that contributing factors may include disordered sleep, atypical eating patterns and challenges associated with engaging in physical activity. It is plausible that goal setting skills may prove an important component in treatment programs aimed to overcome these barriers and develop a healthy and independent lifestyle.

However, a recent review of self-management interventions for students with ASD (Carr et al. 2014) identified a paucity of goal setting research for students on the autism spectrum. Yet, evidence of the success of goal setting techniques has been reported for individuals with mental retardation or cognitive disabilities. Therefore, to address this knowledge gap, we conducted a broader systematic literature search of goal setting research which included an array of participants not restricted by diagnostic category. The aim of this review was to map the current knowledge base regarding goal setting as an intervention, or part thereof, for students with varied additional learning needs and challenges. Given our focus on the use of goal setting as part of individualised selfmanagement training for individuals with ASD, the search was restricted to research employing single-case research designs (SCDs). The ideographic nature of SCD research makes this methodology particularly appropriate when examining the effects of individualised interventions (Southall and
Gast 2011), such as often seen in special education research (Horner et al. 2005). These findings are then discussed with reference to their implications for students with ASD with a view to proposing an agenda for future research in this area. The following research questions were investigated:

1. What are the profiles of participants in goal setting research?

2. How have goal setting interventions been structured?

3. What target behavior was goal setting applied to?

4. Who is involved in setting participant goals (self or other)?

5. Are goal setting skills maintained over time and was generalization assessed?

6. What does the current literature suggest for applying goal setting to participants with ASD?

\section{Method}

Studies were located for this review by conducting a systematic search of peer-reviewed literature published prior to November, 2013. Keywords typically associated with goal setting were identified from existing literature reviews, and a PsycINFO database search was subsequently conducted. The following search terms were queried: "goal setting", "goal attainment" and "goal orientation". A hand search of the reference lists of existing goal setting reviews, published in peer-reviewed journals, was also conducted to identify any additional relevant articles that may have been omitted from the database search results.

The following inclusion criteria were adopted for this review:

1. The study utilised a SCD such as a multiple baseline, reversal or alternating treatment design.

2. The study presented data from each phase in graphical format for each participant.

3. The intervention included a goal setting component.

4. Participants were students engaged in a learning process.

5. Articles were published in English in peer-reviewed journals.

An independent review of both the title and the abstracts was conducted to ensure the reliability of the article selection process. A graduate student familiar with the broader selfmanagement literature was provided a randomly selected sample of $30 \%$ of all search results and examined both the titles and the abstracts to determine whether these articles met the inclusion criteria for further review. Inter-assessor agreement (IOA) for the article selection procedure was determined by dividing the number of agreements by the total number of 
agreements plus disagreements and multiplying by 100 . An IOA of $97 \%$ was achieved for this process.

\section{Results and Discussion}

This search and selection process yielded 38 studies describing research conducted with 186 participants, who ranged in age from 6 to 54 years. Participants were attending school, higher education, elite athlete or sheltered workshop job skills training programs. The 38 studies were conducted by 29 separate research teams in various locations. A total of 30 studies were from within the USA, conducted in the following states: Alabama (2), California (1), Florida (3), Georgia (1), Hawaii (1), Illinois (2), Kansas (2), Louisiana (2), Missouri (1), Montana (1), Nebraska (2), New York (3), Ohio (3), Oklahoma (2), Oregon (1), Tennessee (2) and Washington (1). The remaining eight studies were conducted in the following locations: Canada (3), New Zealand (2) and the UK (3). Further, for one study by researchers from Oregon, data collection was conducted in South Korea.

Table 1 provides a descriptive overview of each study included in the review.

The descriptive statistics obtained from these data are further summarised in Table 2.

\section{What Are the Profiles of Participants in Goal Setting} Research?

Of the 186 participants, 128 were males $(69 \%)$ and 58 were females (31\%). For studies that reported an age range only, we have classified the participants using the uppermost age. Where studies reported an average age, we have classified the participants using the average age provided. The remaining studies provided an age for each participant. Accordingly, there were 82 elementary students aged 6 through 12 years (44\%), 73 high school students aged 13 through 17 years (39\%) and 31 adults aged 18 years or older (17\%).

Participant descriptions were classified using the primary diagnosis provided in the original study. Accordingly, there were 5 participants with autism (3\%), 4 with Asperger's syndrome (AS) (2\%), 14 with ADHD (8\%), 14 with emotional behavioral disorder or difficulties $(8 \%), 45$ with learning disability or difficulties $(24 \%), 21$ with mental retardation (11\%), 12 with non-compliance/conduct disorder (6\%), 1 participant who was manic/depressive (1\%), 2 gifted students (1\%), 15 participants described as typically developing $(8 \%)$, 49 athletes $(26 \%)$ and 4 participants with physical disabilities $(2 \%)$.

Mixed results were reported with young students. Figarola et al. (2008) used goal setting and self-graphing to improve the math fact fluency of three young participants that included a 7 year old with a LD and 7 and 8 year olds with ADHD. A goal was established for the end of the year, and participants graphed their daily performance scores. Participants were given verbal praise for correctly entering their data, as well as for meeting or exceeding their aim line. Results showed that performance met or exceeded goals $83 \%$ of the time for the 8 year-old participant and $90 \%$ of the time for the 7 year old with LD. Modifications in the form of shorter problem sets, verbal prompts and reinforcement were required for the other 7 year-old participant before achieving consistent improvement.

By contrast, Grossi and Heward (1998) reported more consistent results in a study with older participants. Four adults aged 20-37 years old diagnosed with mild mental retardation were included in an intervention that was conducted in a community based restaurant training program. During training, each participant established a goal to increase production, goal setting being guided by the experimenter if the goal appeared unattainable. Participants were taught to self-monitor and record their performance. The authors reported that all participants increased their work productivity without compromising the quality of their work and without achieving complete accuracy in self-recording.

Similarly, Balcazar et al. (1991) reported consistent results and generalization effects among older physically disabled students. Three university students aged in their 20 s and one aged 40 years were included in an intervention that used roleplay to teach the skills necessary for individuals to recruit the help they may need to attain their own self-set personal goals. A goal attainment scale was used to identify either no change, realistic attainment or best anticipated attainment outcomes, and the authors reported that for the 20 goals that were set by the four participants, realistic attainment was reported eight times and best anticipated attainment was achieved for seven goals. No change was reported in only five instances. A generalization probe also reported that intervention effects were observed in natural situations in which participants asked for help.

To date, intervention research has been conducted across a broad age range of participants. While less consistency has been demonstrated with younger children, the literature we reviewed has indicated preliminary support for goal setting employed across all ages. Importantly, these findings indicate that adults have been able to learn and apply goal setting skills. While our search revealed little research conducted among participants diagnosed with ASD, goal setting has been employed in successful interventions with participants who experience learning difficulties or cognitive challenges. These preliminary findings may present significant implications for future research with this population as the behavioral issues often exhibited by individuals with ASD that may serve to mask a self-determination skill deficit amenable to goal setting intervention. 







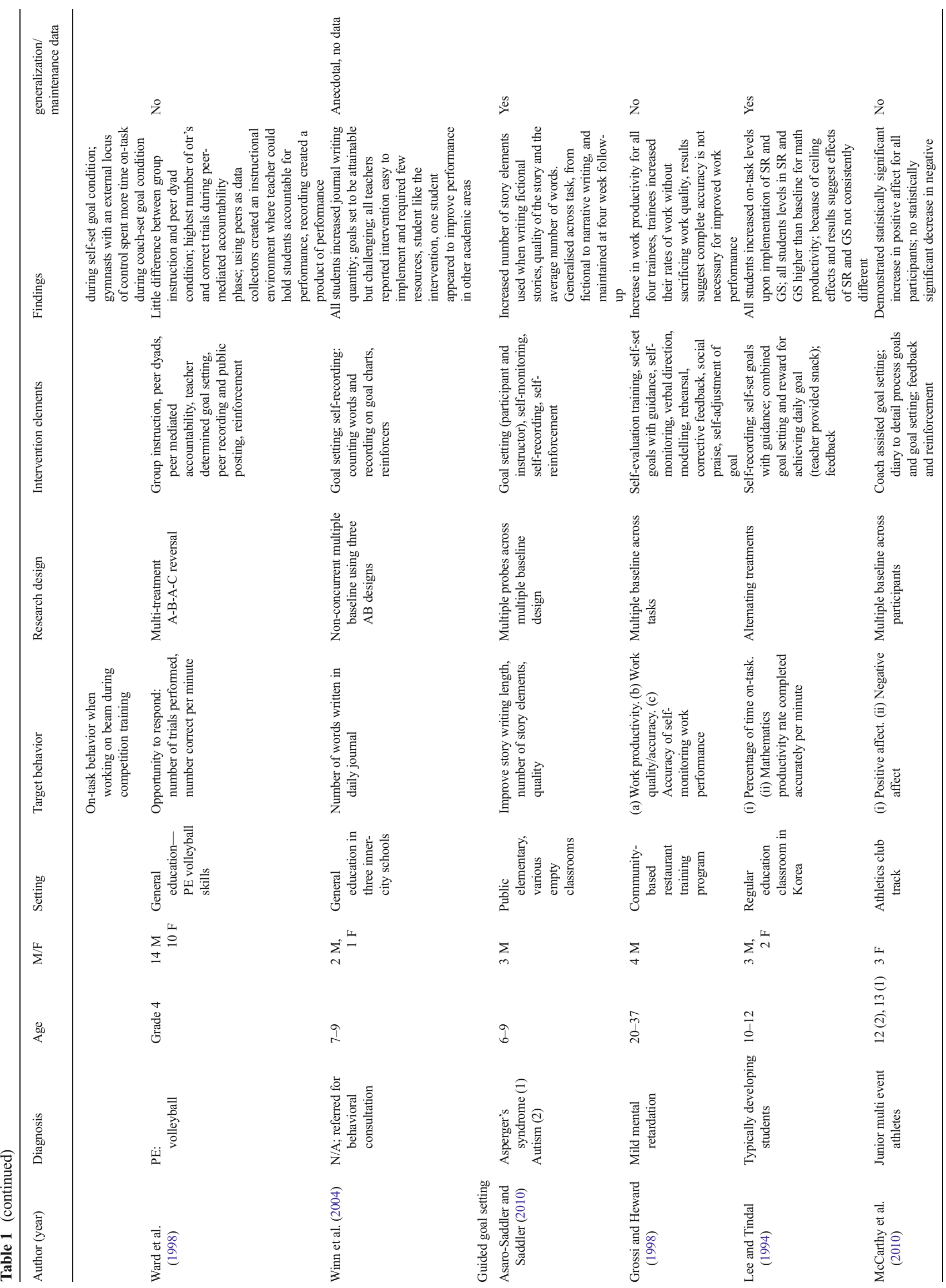




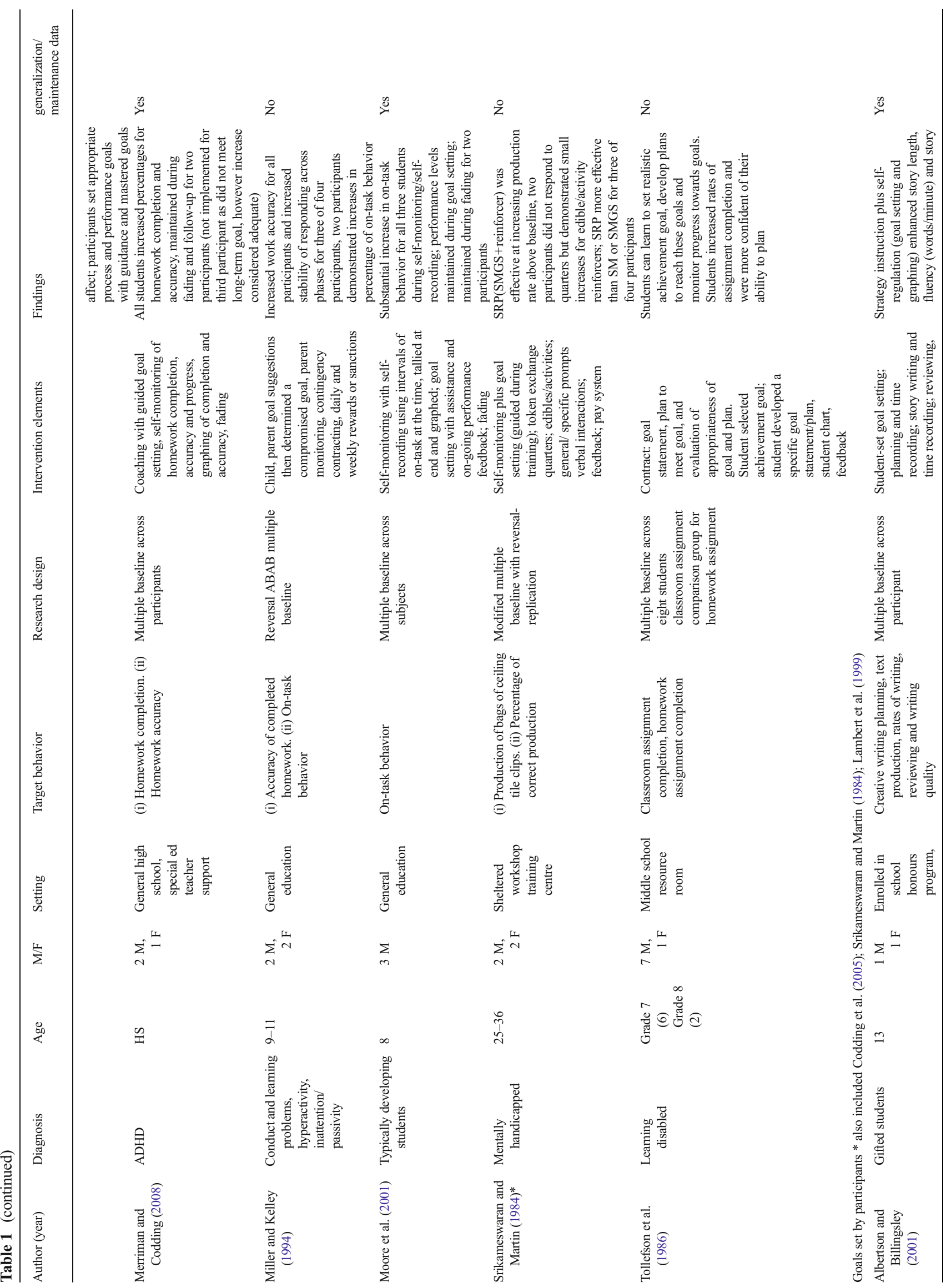




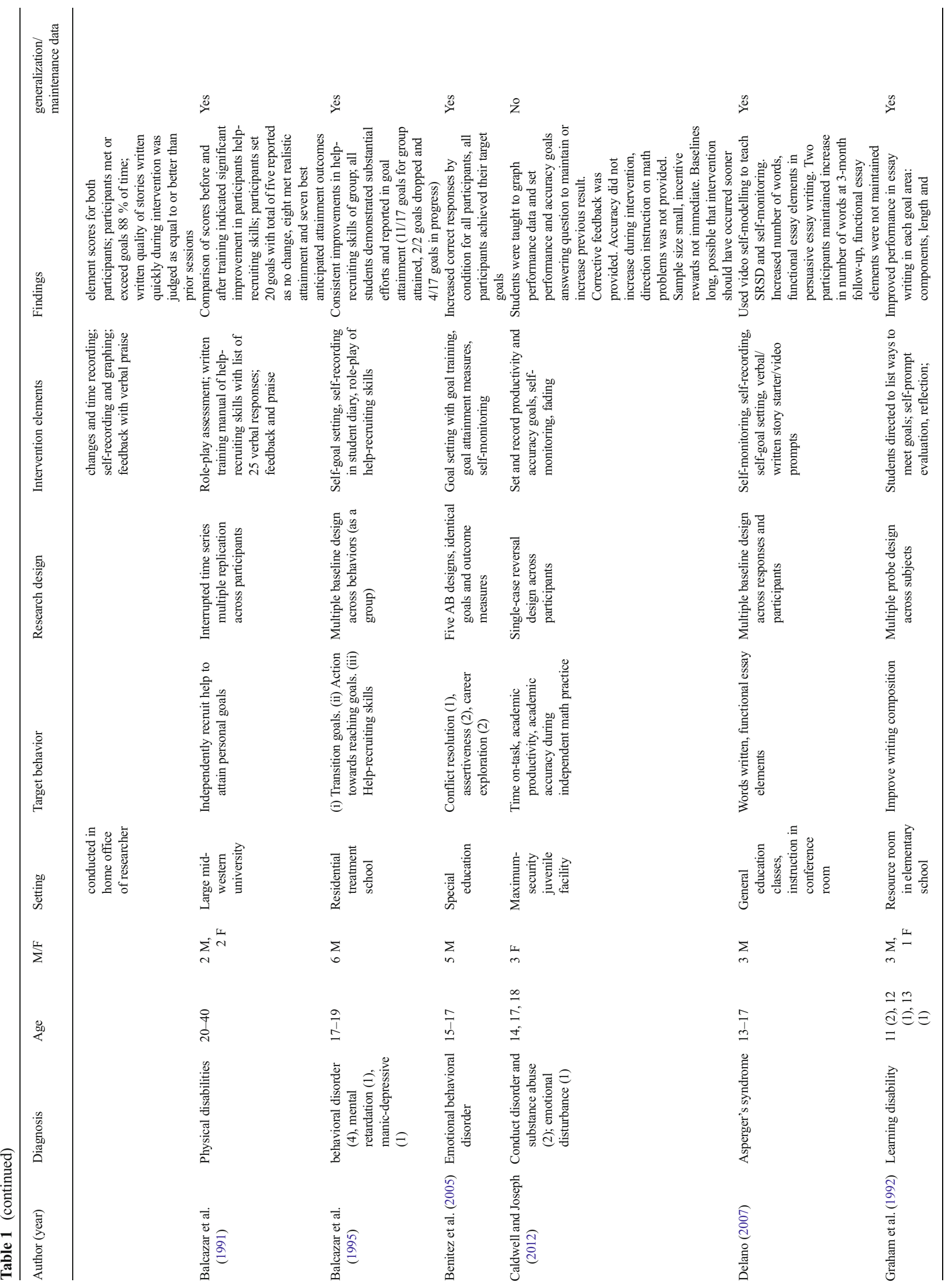




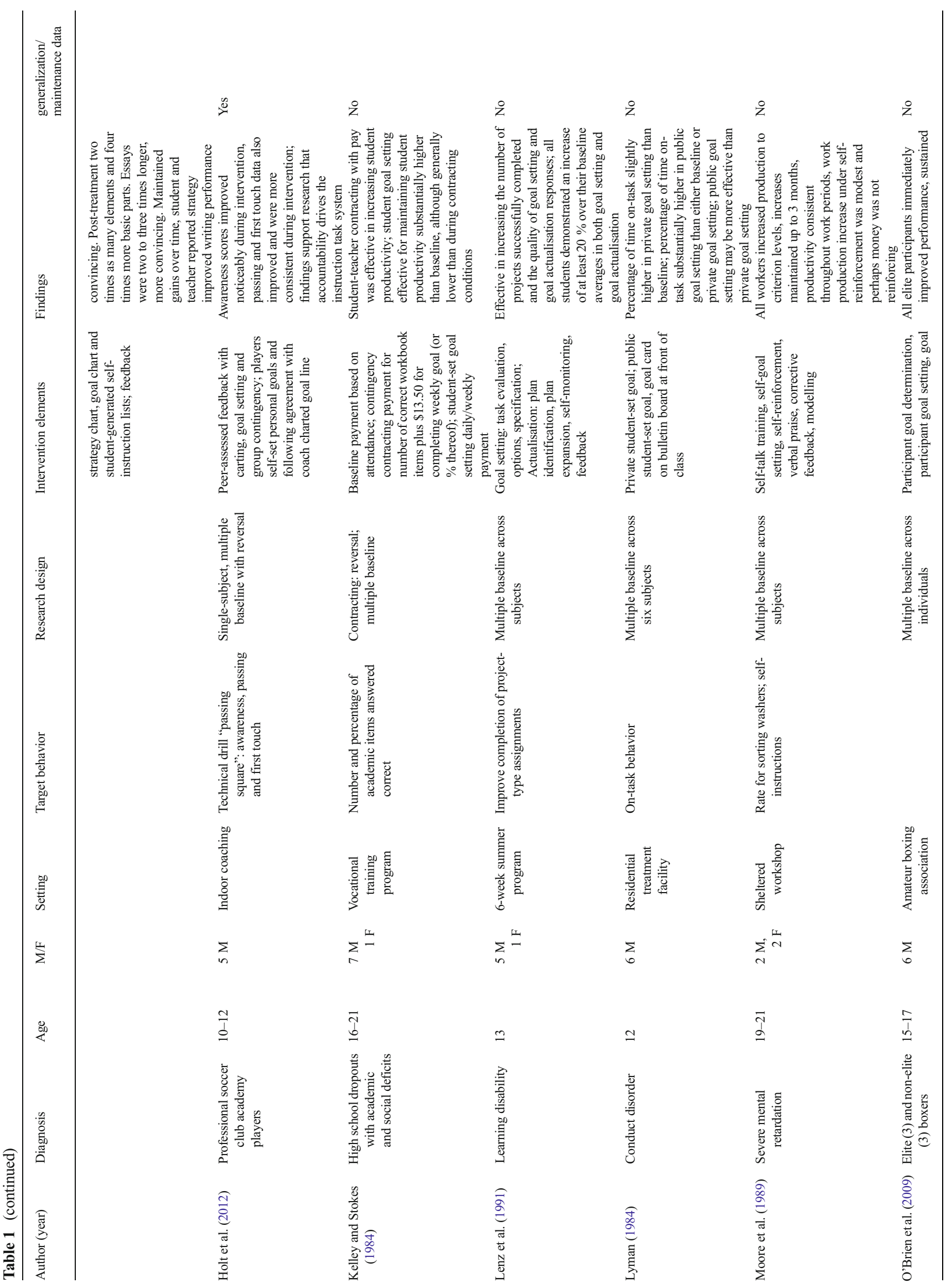




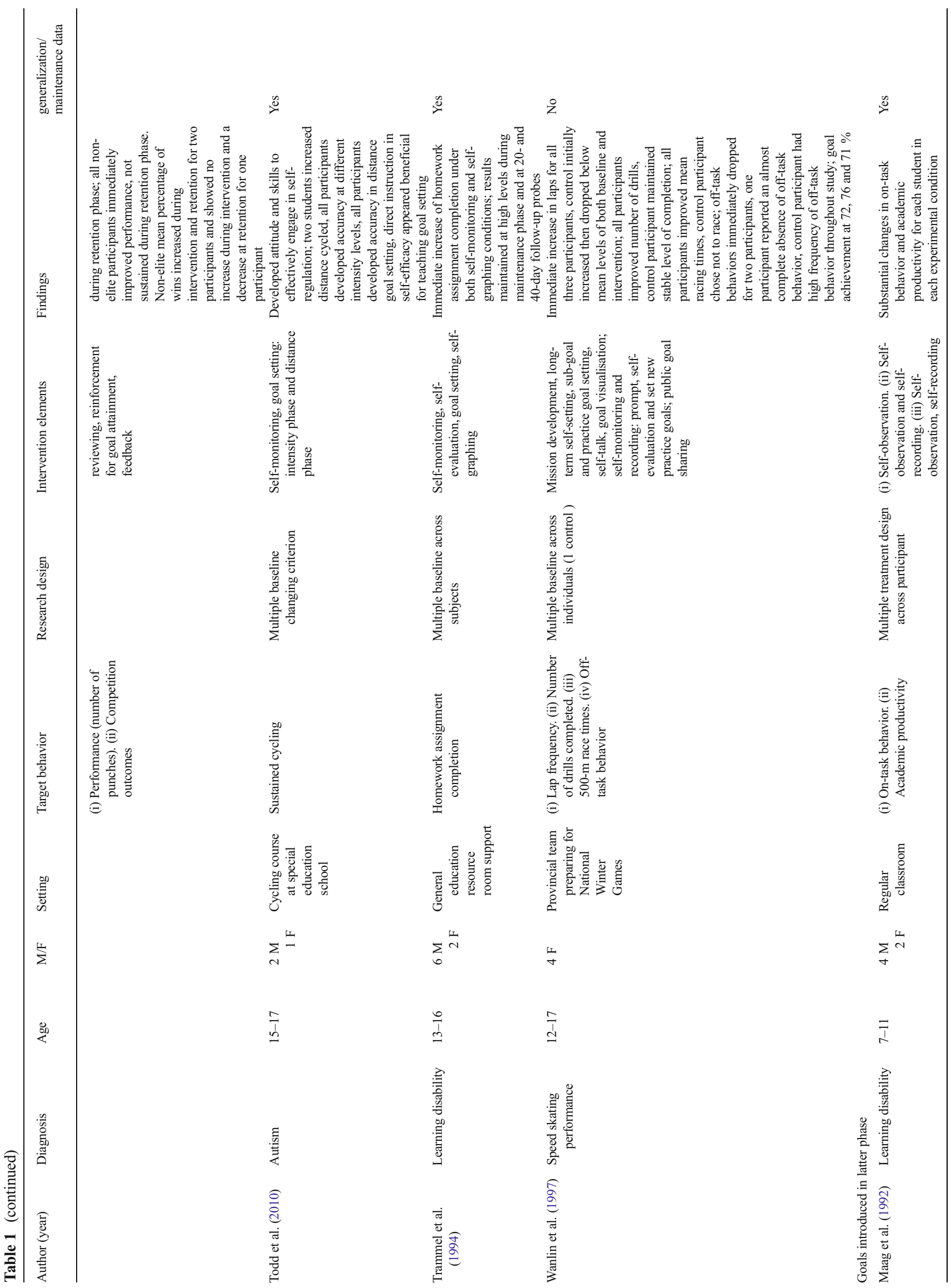




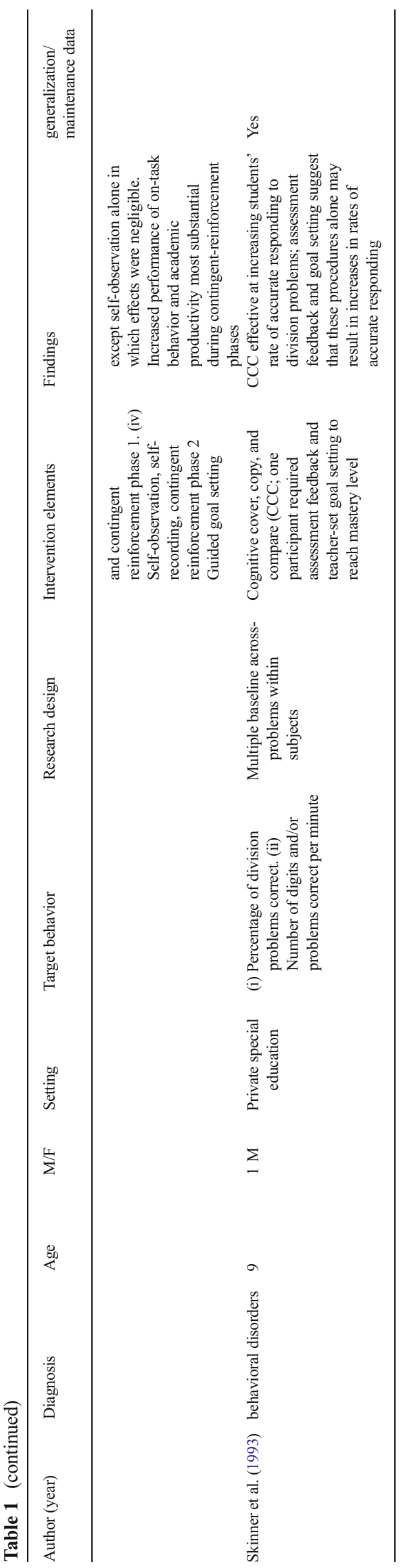

How Have Goal-Setting Interventions Been Structured?

Interventions that included goal setting as part of treatment packages and alongside other intervention components were frequently described. These included contracting (3), selfmonitoring (25), reinforcement (15) and feedback (17). The use of technology was also described and included computer instruction (1) and video modelling (1). An approach to teach goal setting was described in six studies (16\%), and the use of self-regulated strategy development (SRSD) techniques was reported in two studies ( $5 \%$ ). Public goal sharing was included as an intervention element in four studies (11\%).

Lyman (1984) explored the effects of private student-set goals and public sharing of student-set goals with six students schooled in a residential treatment facility as a result of conduct disorder. During the public condition, a goal card was placed on the bulletin board at the front of the class. Participants reportedly spent a slightly higher percentage of time attending to task during the private goal setting condition and substantially more time on task upon introduction of public goal sharing.

Goal setting was introduced during the latter stage of intervention in two studies $(5 \%)$. One study examined the effects of self-monitoring with contingent reinforcement under two conditions: comparison to prior performance and contingent to meeting a goal (Maag et al. 1992). Another study introduced goals in the latter phase in order for one participant to achieve mastery of math division (Skinner et al. 1993).

Maag et al. (1992) introduced goal setting in the final phase of an intervention that included the following phases: a self-observation condition; self-observation and self-recording; self-observation (reversal), selfrecording and contingent verbal reinforcement for performance improvement; and self-observation, selfrecording and contingent reinforcement using teacherand student-set goals for successive increases in mathematics problem task performance. The largest gain in academic productivity occurred during the phase of contingent reinforcement plus goal setting, during which the teacher not only provided verbal reinforcement for an increase over prior performance but also provided verbal encouragement in the event a goal was not met. The authors concluded that treatment effects can be increased by the simultaneous use of goal setting. However, the effect of goal setting alone was not explored.

While the original authors of these 38 studies have consistently reported positive treatment effects, the majority of the studies have confounded goal setting with other dependant variables. Three studies were identified which enable the effectiveness of goal setting alone to be examined. Lambert et al. (1999) compared self-set goals with coach-set goals, and 
Table 2 Summary of descriptive statistics

\begin{tabular}{|c|c|c|}
\hline & Descriptor & Participant numbers \\
\hline \multirow[t]{2}{*}{ Sex } & Male & 128 \\
\hline & Female & 58 \\
\hline \multirow[t]{3}{*}{ Age } & School aged (6-12 years) & 82 \\
\hline & Adolescence (13-17 years) & 73 \\
\hline & Adulthood (18 years and older) & 31 \\
\hline \multirow[t]{12}{*}{ Diagnosis } & Autism & 5 \\
\hline & Asperger's syndrome & 4 \\
\hline & ADHD & 14 \\
\hline & Emotional behavioral disorder & 14 \\
\hline & Learning disability & 45 \\
\hline & Mental retardation & 21 \\
\hline & Non-compliance/conduct & 12 \\
\hline & Manic depressive & 1 \\
\hline & Giftedness & 2 \\
\hline & Typically developing & 15 \\
\hline & Athletics & 49 \\
\hline & Physical disability & 4 \\
\hline \multirow[t]{8}{*}{ Method } & Taught prerequisite skills & 1 \\
\hline & Taught goal setting & 6 \\
\hline & Taught self-regulated strategy development (SRSD) & 2 \\
\hline & Goals set by other & 11 \\
\hline & Guided goal setting & 9 \\
\hline & Guided goal setting, set by participant & 20 \\
\hline & Public goal sharing & 4 \\
\hline & Goals introduced in latter phase & 2 \\
\hline \multirow[t]{6}{*}{ Other components } & Contracting & 3 \\
\hline & Self-monitoring & 25 \\
\hline & Reinforcement & 15 \\
\hline & Feedback & 17 \\
\hline & Used computer instruction & 1 \\
\hline & Used video modelling & 1 \\
\hline \multirow[t]{12}{*}{ Target behavior } & Transition planning & 2 \\
\hline & Problem behavior & 8 \\
\hline & Mathematics & 9 \\
\hline & Writing & 6 \\
\hline & Reading & 1 \\
\hline & Academics - all subjects & 3 \\
\hline & Homework & 4 \\
\hline & Projects & 1 \\
\hline & Social skills & 1 \\
\hline & Athletics & 7 \\
\hline & Development of physical activity skills & 1 \\
\hline & Vocational tasks & 4 \\
\hline
\end{tabular}

both Maag et al. (1992) and Skinner et al. (1993) introduced a goal condition additively to achieve an effective treatment thereby enabling intervention effects to be measured before and after the introduction of goal setting. In each case, goal setting was associated with clear behavioral gains.
What Types of Target Behavior Was Goal Setting Applied To?

These interventions addressed a variety of target behaviors including transition planning (2), decreasing problem 
behavior (8), mathematics (9), writing (6), reading (1), all academic subjects (3), homework (4), projects (1), social skills (1), athletic performance (7), development of physical activity skills (1) and vocational tasks (4). Target behavior was plotted by number of participants, as illustrated in (Fig. 1).

Barry and Messer (2003) incorporated goal setting with self-management to increase on-task behavior and academic performance and decrease disruptive behavior in an intervention conducted with five boys with ADHD. The teacher set participant goals using the approximate average for the class in an intervention that included self-recording, teacher prompting and reinforcement. Goals for academic achievement and on-task behaviors were gradually increased during fading. While results again showed this to be an effective intervention procedure, researchers noted that gradual fading of supports was necessary to ensure maintenance.

Tollefson et al. (1986) targeted an increase in completion of classroom assignments and an increase in homework assignment completion for eight middle school students described as learning disabled. During training with the research assistant, each student selected an achievement goal: daily or weekly inclass assignments, or homework assignments for the week, and developed a goal statement of what was required and by when. A study plan was specified, and each student selfmonitored work completion. Subsequently, students met with the research assistant to evaluate the goal and the plan, addressing reasons for success or failure in goal attainment. A homework contract phase was introduced for four students, intended to promote generalization of goal implementation skills. Three students demonstrated a marked increase in homework assignment completion. The authors reported that time spent teaching goal setting and goal implementation strategies not only increased the rate of assignment completion but also made students more confident in their ability to plan.

A goal setting model that included goal determination, goal setting and goal reviewing was used to examine the cumulative effects on skill performance among six high school boxers (O’Brien et al. 2009). During goal determination, participants met with the researcher to determine a self-generated performance behavior. All participants rated the number of punches landed as most important, thus determining this as the target behavior. During goal setting, a numeric system to measure changes in the participants' target expectations over time as well as a means to measure progress during intervention was developed. Three elite level participants immediately improved performance, and improvement was sustained during a follow-up phase. However, while the three non-elite participants also immediately improved performance, their increase was not sustained during follow-up.

Individuals with ASD are often described as having an uneven profile of executive functioning skills, an area of importance for achieving academic or vocational success (Geller and Greenberg 2010). While high-functioning students on the spectrum may be academically capable, problems with organisation and planning may negatively impact success in higher education or vocational settings and present a challenge for independent functioning. The application of goal setting to behavior management, attention to task and time management described in the existing literature raises the possibility that effective goal setting instruction may be beneficial to students with ASD in learning skills necessary to

\section{Target behavior by participants}

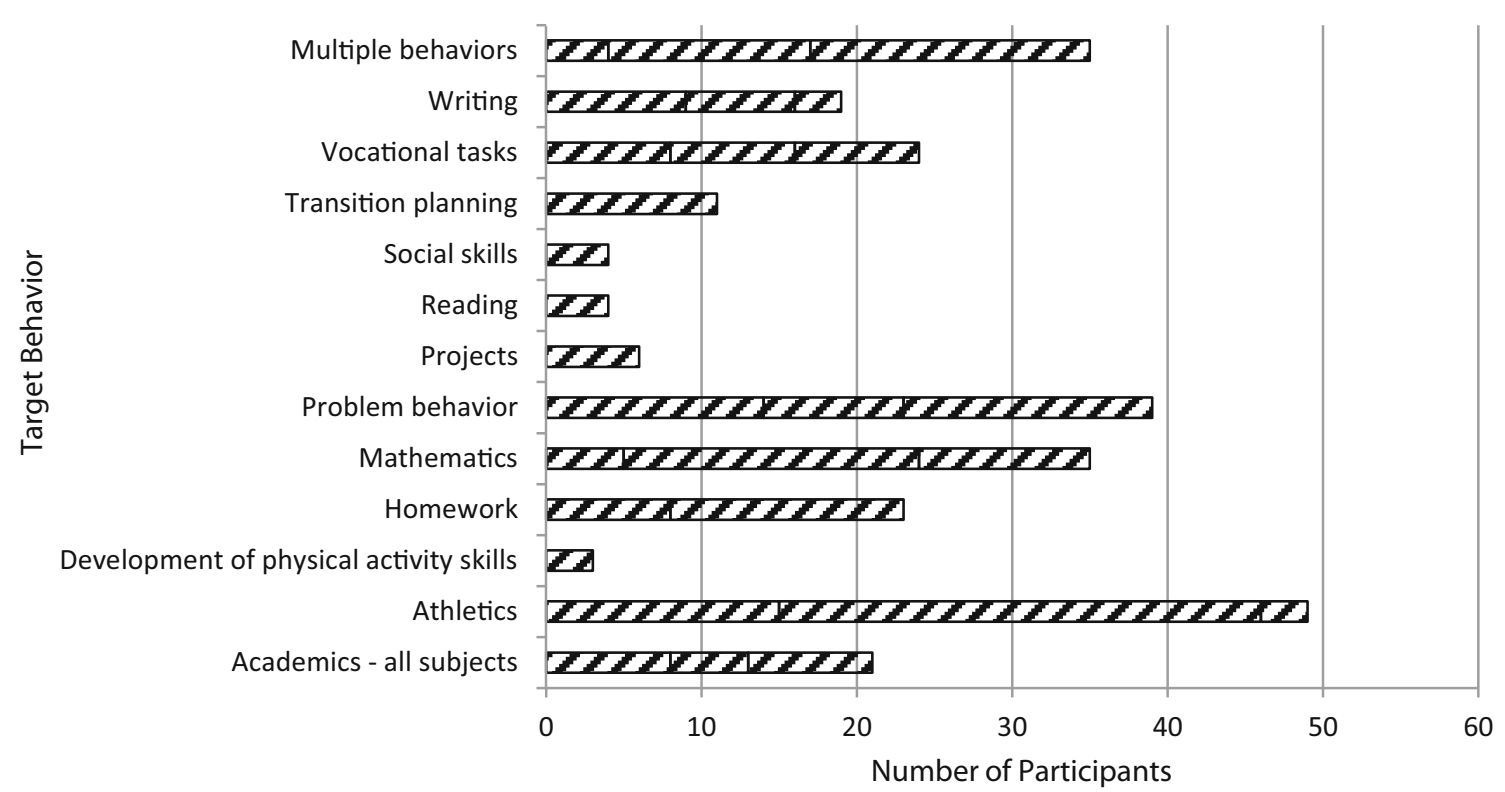

Fig. 1 Target behavior by participants 
overcome these challenges and to perform tasks independently.

Who Is Involved in Setting Participant Goals?

The studies in this data set described a variety of stakeholders involved in the goal setting process. Twenty studies (53\%) described goal setting by the participants, 9 studies (24\%) described the participant setting goals under guidance, and in 11 studies ( $29 \%$ ), goals were set by someone other than the participant.

Two studies employed an alternating treatment design to compare the effects of goal setting by either the experimenter/ coach with goals that were set by the participant (Codding et al. 2005; Lambert et al. 1999). While Codding and colleagues (2005) reported that participants not only performed better during the student selected goals condition but also favoured this condition over the experimenter-selected goal condition, Lambert and colleagues (1999) reported that self-set and coach-set goals functioned differently depending on the participants' locus of control. In particular, an internal locus of control was associated with greater gains under a selfset goal condition, and an external locus of control was associated with greater gains under a coach-set goal condition.

Participant descriptions were plotted against the differences in the identity and role of the goal setter (self vs other vs guidance provided) for the studies reviewed, as illustrated in Fig. 2. The graph illustrates a potpourri of self, other and guided approaches to goal setting. The exclusive use of independently set goals was noted amongst participants described either as gifted or physically disabled, while goals were either set independently by the participants or under guidance for participants with ASD, AS, conduct disorder and students with manic depression. Typically developing students in this data set did not set goals independently and received guidance with setting goals only marginally more frequently than having goals set by an adult. A few athletes received guidance with goal setting, and athletes set goals independently in just over one third of the data. The majority of participants with learning disabilities self-set goals, although both guidance and goals set by another adult were observed. Few students with ADHD set goals independently, and occasional provision of guidance was observed in these studies though the majority of these participants had goals set by an adult. This diversity in approaches may reflect different purposes on the part of the researchers when adopting goal setting in interventions. For studies targeting increased performance, such as in the case of athletes, it may arguably be less relevant for the participants to independently set their own performance goals. By contrast, where the aim of the intervention is to enhance independent functioning, developing social skills, transition planning or reducing problem behavior for example, teaching participants to set their own goals either independently or with guidance may be of greater relevance.

By way of example, three non-verbal high school students diagnosed with ASD were included in an intervention that aimed to increase participation in sustained physical activity (Todd et al. 2010). The students possessed the physical skills required to cycle and were able to discriminate correctly between more or less necessary to set distance goals. Prior to

\section{Goal setting method used by participants}

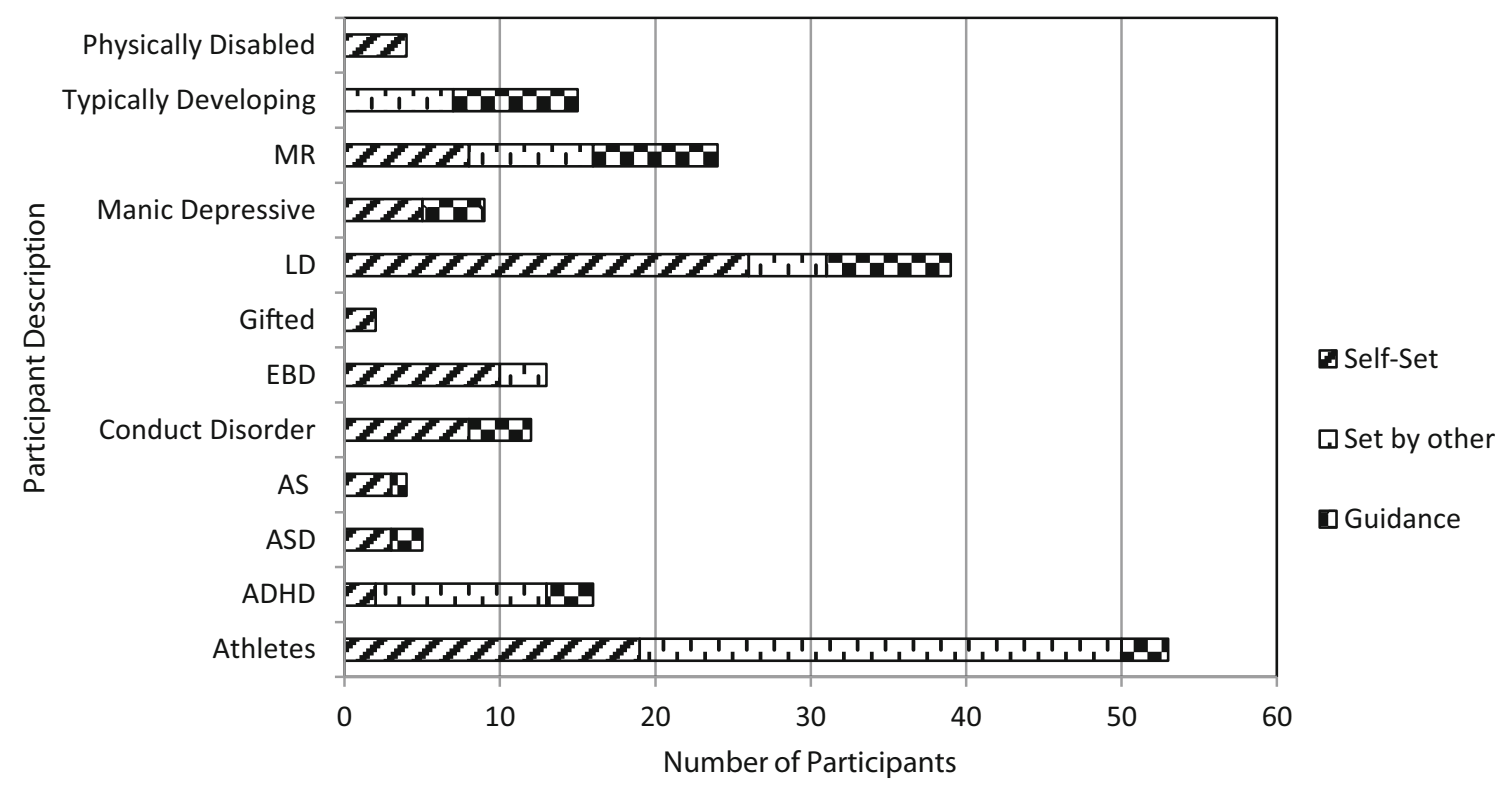

Fig. 2 Goal setting method used by participants 
independently setting cycling distance goals, participants were given guidance to understand their cycling capabilities and were taught to self-monitor. All three students developed accuracy in setting both distance and intensity goals, and two of the students increased the distance they cycled.

However, for interventions in which successful completion of task is less related to attaining independence, the identity of the goal setter may be less significant. For example, guided goal setting, combined with self-monitoring and performance feedback, formed the basis of a coaching intervention in an intervention conducted with three high school students with ADHD (Merriman and Codding 2008). An initial goal setting meeting was conducted between each student and the coach. Students used their baseline data to set goals for mathematics homework completion and accuracy, and the coach gave guidance in the event of unrealistic goal suggestions. Coaching was conducted daily with feedback and goal reformulation, and praise for progress was provided until the students achieved their long-term goals. During systematic fading, coaching sessions went to alternate days then weekly until eventual termination. Results showed that coaching improved the completion and accuracy of homework for all three participants, with improvements maintained during fading and follow-up for the two participants that met their long-term goals.

In contrast, interventions that do not impact the participants' ability to achieve independent functioning may not require the participants themselves to set goals in order to achieve positive outcomes. For example, Brobst and Ward (2002) reported a study with three teenaged female soccer players to increase performance of existing ball skills in both practice sessions and games. The head coach and the researcher established a performance level for the targeted skills, and an intervention package that included public posting, goal setting and oral feedback was implemented. Both the goal and the rationale behind it were explained to the participants, and practice results were reported on a performance chart displayed near the playing field. Players were praised for meeting goals and given encouragement if they did not. Results demonstrated improvement during practice. Generalization results were less consistent, and improvement during games was apparent for only one of the three ball skills.

Are Goal Setting Effects Maintained Over Time and Was generalization Assessed?

While frequent informal reports of generalization and maintenance over time were included by the original authors of studies in this set, data confirming such effects was reported in 18 of the 38 studies ( $47 \%$ ). Three of the 38 studies included participants with ASD (Asaro-Saddler and Saddler 2010; Delano 2007; Todd et al. 2010), and notably, all three of these articles included data for either generalization or maintenance of treatment effects over time.

Inspection of generalization and maintenance data for the participants with ASD revealed variable findings. AsaroSaddler and Saddler (2010) included a generalization task in an intervention conducted with two elementary students with $\mathrm{AS}$, and one with autism, in which the writing requirement altered from fiction to personal recount. While two participants appeared to successfully generalize writing skills to the new task, one participant included a fictional name rather than "I". The authors reported that participants may not have clearly distinguished the required difference. Similarly, data gathered to explore maintenance of treatment effects over time also resulted in variable findings. Todd et al. (2010) examined cycling distance goals in the maintenance phase of an intervention with three non-verbal teens. Gains in excess of baseline were maintained for two of the three participants during the phase. Delano (2007) collected follow-up data at both 1week and 3-month time frames for three teens with AS. Although a gain in the number of words written was maintained by all three participants at 3 months, the number of functional essay elements was not maintained. Delano (2007) suggested that a longer intervention period may be required. Asaro-Saddler and Saddler (2010) also collected maintenance probes after 4 weeks and acknowledged the limitation of their data as continued gains beyond this time frame remain unknown.

Stokes and Baer (1977) described generalization across subjects, settings, people, behaviors and/or time as the occurrence of relevant behavior under different untrained conditions in the absence of conditions that had been scheduled during training. At that time, attention was drawn to the importance of actively programming to achieve generalization, rather than to passively expect it as an outcome of training procedures. In addition, the use of stimuli found in the generalization settings, which included the role of peers as tutors, was highlighted as significant to future research when structuring training sessions.

Authors of the original studies from our broader data set generally concur that graduated fading is necessary in order to maintain intervention effects over time or to observe generalization of effects to new settings or behaviors. Several studies reported successful maintenance of treatment effects over time among all participants in research that included systematic stimulus fading (Moore et al. 2001; Merriman and Codding 2008).

\section{Conclusions}

Our aim in this study was to map the existing single-subject research evidence for interventions that have included a goal 
setting component with a view to informing a research agenda for participants with ASD. This data set as a whole provides preliminary support for the effectiveness of goal setting techniques in a wide variety of interventions. However, to date, little research on goal setting has been performed with individuals who have a diagnosis of ASD.

Second, in the research identified, goal setting effects have almost always been confounded with interventions typically involving a combination of components additional to goal setting. The most common of these, self-monitoring, was included in two thirds of the interventions. Several of these studies noted that participants value both establishing their goal independently and self-monitoring their behavior. Feedback was also included in almost half of the interventions, and again, original author reports suggest that information derived from feedback played a significant role in positive intervention outcomes.

Southall and Gast (2011), in their qualitative review of selfmanagement interventions for students with ASD, emphasised the need for researchers to examine the effects of specific components of current self-management intervention packages to identify the relative contribution of each. Our findings support this conclusion, highlighting in particular the need to explore the contribution goal setting has, either in isolation or in combination with other intervention components, on intervention outcomes and on the development of self-determination more generally.

Another important observation arising from this data set concerns the generalization and maintenance of observed changes. Goal setting skill training may be an important component of treatment packages that aim to develop independent functioning for participants with $\mathrm{ASD}$, and effective goal setting may be a vital skill for high-functioning students who pursue higher education. Given that goal setting skills are developed over time, it appears particularly important to gather generalization and maintenance data. While limited in volume, the preliminary maintenance data for participants with ASD is variable, including accounts of maintenance failure post-intervention. Accordingly, we reiterate the importance that future research includes longer intervention phases, in addition to programming for generalization and maintenance over longer time frames and/or including peers.

With respect to how participants have been involved in the goal setting process within an intervention, no clear pattern is evident in our data set. The basis on which researchers have decided either to set goals themselves or how and to what extent to involve the participants in this process is unclear, and importantly, the implications of these decisions are largely unexplored. This review has identified goal setting research that has been conducted successfully with a wide variety of individuals engaged in the process of learning. Although the authors of this work have consistently reported successful outcomes in interventions that have included goal setting and these accounts suggest that goal setting skills are teachable, further research that explores the relative merit of engaging participants in the goal setting process and that identifies effective strategies for teaching goal setting appears warranted.

Finally, although the literature has included successful accounts of individuals improving sports performance through the use of goal setting skills, there is a paucity of research with participants with ASD regarding the development and/or improvement of skills required to promote a physically active lifestyle. This finding is of significance to this population given the recent reports of elevated chance of developing obesity, in addition to the loss of opportunity to engage in social interactions with typically developing peers. Research that explores treatments aimed to overcome challenges that may result from a sedentary lifestyle, food selectivity or disrupted sleep appears justified.

\section{Proposed Research Agenda for Participants with ASD}

While limited in quantity, the SCD research with participants on the autism spectrum included in this review suggests that goal setting instruction may be successful with this population. We propose the following foci as elements of future research to aid in developing treatment packages that foster independent living:

1. Research that explores the role of goal setting in isolation or in combination with other intervention components

2. Research that explores the generalization and maintenance effects of goal setting interventions, particularly including peers as tutors to assist in programming generalization

3. Research that explores how to best teach goal setting skills to participants with a view to attaining the ability to perform this skill independently

4. Research that explores the relative effects of goal setting by the participants themselves compared to goals set by other stakeholders

\section{References}

* Studies included in the review

*Albertson, L. R., \& Billingsley, F. (2001). Using strategy instruction and self-regulation to improve gifted students' creative writing. The Journal of Secondary Gifted Education. doi:10.4219/jsge-2000648. 
Algozzine, B., Browder, D., Karvonen, M., Test, D. W., \& Wood, W. M. (2001). Effects of interventions to promote self-determination for individuals with disabilities. Review of Educational Research. doi: $10.3102 / 00346543071002219$.

*Asaro-Saddler, K., \& Saddler, B. (2010). Planning instruction and selfregulation training: effects on writers with autism spectrum disorders. Exceptional Children. doi:10.1177/1053451208330895.

*Balcazar, F. E., Fawcett, S. B., \& Seekins, T. (1991). Teaching people with disabilities to recruit help to attain personal goals. Rehabilitation Psychology. doi:10.1037/h0079072.

*Balcazar, F. E., Keys, C. B., \& Garate-Serafini, J. (1995). Learning to recruit assistance to attain transition goals: a program for adjudicated youth with disabilities. Remedial and Special Education. doi:10. 1177/074193259501600407.

*Barry, L. M., \& Messer, J. J. (2003). A practical application of selfmanagement for students diagnosed with attention-deficit/hyperactivity disorder. Journal of Positive Behavior Interventions. doi:10. 1177/10983007030050040701.

*Benitez, D., Lattimore, J., \& Wehmeyer, M. (2005). Promoting the involvement of students with emotional and behavioral disorders in career and vocational planning and decision-making: the selfdetermined career development model. Behavioral Disorders, 30, 431-447.

*Brobst, B., \& Ward, P. (2002). Effects of public posting, goal setting, and oral feedback on the skills of female soccer players. Journal of Applied Behavior Analysis. doi:10.1901/jaba.2002.35-247.

*Caldwell, S., \& Joseph, L. M. (2012). Helping female juveniles improve their on-task behavior and academic performance using a selfmanagement procedure in a correctional facility. Contemporary School Psychology, 16, 61-74.

Carr, M., Moore, D. W., \& Anderson, A. (2014). Self-management interventions on students with autism: a meta-analysis of singlesubject research. Exceptional Children. doi:10.1177/ 0014402914532235. in press.

*Codding, R. S., Lewandowski, L., \& Eckert, T. (2005). Examining the efficacy of performance feedback and goal-setting interventions in children with ADHD: a comparison of two methods. Journal of Evidence-Based Practices for Schools, 6, 42-58.

Copeland, S. R., \& Hughes, C. (2002). Effects of goal setting on task performance of persons with mental retardation. Education and Training in Mental Retardation, 37, 40-54.

Curtin, C., Jojic, M., \& Bandini, L. G. (2014). Obesity in children with autism spectrum disorder. Harvard Review of Psychiatry. doi:10. 1097/HRP.0000000000000031.

*Delano, M. E. (2007). Improving written language performance of adolescents with Asperger syndrome. Journal of Applied Behavior Analysis. doi:10.1901/jaba.2007.50-06.

*Duhon, G. J., Noell, G. H., Witt, J. C., Freeland, J. T., Dufrene, B. A., \& Gilbertson, D. N. (2004). Identifying academic skill and performance deficits: the experimental analysis of brief assessments of academic skills. School Psychology Review, 33, 429-443.

*Farrell, A., \& McDougall, D. (2008). Self-monitoring of pace to improve math fluency of high school students with disabilities. Behavior Analysis in Practice, 1(2), 26-35.

Field, S., Martin, J., Miller, R., Ward, M., \& Wehmeyer, M. (1998). Selfdetermination for persons with disabilities: a position statement of the division on career development and transition. Career Development for Exceptional Individuals. doi:10.1177/ 088572889802100202.

*Figarola, P. M., Gunter, P. L., Reffel, J. M., Worth, S. R., Hummel, J., \& Gerber, B. L. (2008). Effects of self-graphing and goal setting on the math fact fluency of students with disabilities. Behavior Analysis in Practice, 1(2), 36-41.

Fowler, C. H., Konrad, M., Walker, A. R., Test, D. W., \& Wood, W. M. (2007). Self-Determination interventions' effects on the academic performance of students with developmental disabilities. Education and Training, 42, 270-285.

Geller, L. L., \& Greenberg, M. (2010). Managing the transition process from high school to college and beyond: challenges for individuals, families, and society. Social Work in Mental Health. doi:10.1080/ 15332980902932466.

*Graham, S., MacArthur, C., Page-Voth, V., \& Schwartz, S. (1992). Improving the compositions of students with learning disabilities using a strategy involving product and process goal setting. Exceptional Children, 58(4), 322.

*Gross, T. J., \& Duhon, G. (2013). Evaluation of computer-assisted instruction for math accuracy intervention. Journal of Applied School Psychology. doi:10.1080/15377903.2013.810127.

*Grossi, T. A., \& Heward, W. L. (1988). Using self-evalutation to improve the work productivity of trainees in a community-based restaurant training program. Education and Training in Mental Retardation and Developmental Disabilities. doi:10.1080/ 153779032013.810127.

Halpern, A. S. (1994). The transition of youth with disabilities to adult life: a position statement of the Division on Career Development and Transition, The Council for Exceptional Children. Career Development for Exceptional Individuals. doi:10.1177/ 088572889401700201.

*Hanel, F., \& Martin, G. (1980). Self-monitoring, self-administration of token reinforcement, and goal-setting to improve work rates with retarded clients. International Journal of Rehabilitation Research. doi:10.1017/00004356-198012000-00004.

*Holt, J. E., Kinchin, G., \& Clarke, G. (2012). Effects of peer-assessed feedback, goal setting and a group contingency on performance and learning by $10-12$-year-old academy soccer players. Physical Education \& Sport Pedagogy. doi:10.1080/17408989.2012.690568.

Horner, R. H., Carr, E. G., Halle, J., McGee, G., Odom, S. L., \& Wolery, M. (2005). The use of single-subject research to identify evidencebased practice in special education. Exceptional Children, 71, 165179.

*Kelley, M. L., \& Stokes, T. F. (1984). Student-teacher contracting with goal setting for maintenance. Behavior Modification. doi:10.1177/ 01454455840082005.

Konrad, M., Fowler, C. H., Walker, A. R., Test, D. W., \& Wood, W. M. (2007). Effects of self-determination interventions on the academic skills of students with learning disabilities. Learning Disabilitiy Quarterly. doi:10.2307/30035545.

*Lambert, S. M., Moore, D. W., \& Dixon, R. S. (1999). Gymnasts in training: the differential effects of self-and coach-set goals as a function of locus of control. Journal of Applied Sport Psychology. doi:10.1080/10413209908402951.

*Lee, C., \& Tindal, G. A. (1994). Self-recording and goal-setting: effects on on-task and math productivity of low-achieving Korean elementary school students. Journal of Behavioral Education. doi:10.1007/ bf01539545.

*Lenz, B. K., Ehren, B. J., \& Smiley, L. R. (1991). A goal attainment approach to improve completion of project-type assignments by adolescents with learning disabilities. Learning Disabilities Research \& Practice, 6, 166-176.

Locke, E., \& Latham, G. P. (2002). Building a practically useful theory of goal setting and task motivation: a 35-year odyssey. American Psychologist. doi:10.1037//0003-066X.57.9.705.

Locke, E., Shaw, K. N., Saari, L. M., \& Latham, G. P. (1981). Goal setting and task performance: 1969-1980. Psychological Bulletin. doi:10. 1037//0033-2909.90.1.125.

*Lyman, R. D. (1984). The effect of private and public goal setting on classroom on-task behavior of emotionally disturbed children. Behavior Therapy. doi:10.1016/s00057894(84)80008-8.

*Maag, J. W., Rutherford, R. B., \& DiGangi, S. A. (1992). Effects of selfmonitoring and contingent reinforcement on on-task behavior and 
academic productivity of learning-disabled students: a social validation study. Psychology in the Schools. doi:10.1002/15206807(199204)2-1:2<157.

*McCarthy, P. J., Jones, M. V., Harwood, C. G., \& Davenport, L. (2010). Using goal setting to enhance positive affect among junior multievent athletes. Journal of Clinical Sport Psychology, 4, 53-68.

*Merriman, D. E., \& Codding, R. S. (2008). The effects of coaching on mathematics homework completion and accuracy of high school students with attention-deficit/hyperactivity disorder. Journal of Behavioral Education. doi:10.1007/ s10864-008-9072-3.

*Miller, D. L., \& Kelley, M. Lou. (1994). The use of goal setting and contingency contracting for improving children's homework performance. Journal of Applied Behavior Analysis. doi:10.1901/jaba. 1994.27-73.

*Moore, S. C., Agran, M., \& Fodor-Davis, J. (1989). Using selfmanagement strategies to increase the production rates of workers with severe handicaps. Education and Training in Mental Retardation, 24, 324-332.

*Moore, D. W., Prebble, S., Robertson, J., Waetford, R., \& Anderson, A. (2001). Self-recording with goal setting: a self-management programme for the classroom. Educational Psychology: An International Journal of Experimental Educationanal Psychology. doi:10.1080/01443410123466.

*O'Brien, M., Mellalieu, S., \& Hanton, S. (2009). Goal-setting effects in elite and nonelite boxers. Journal of Applied Sport Psychology. doi: 10.1080/10413200903030894.

Palmer, S. B., \& Wehmeyer, M. L. (2003). Promoting self-determination in early elementary school: teaching self-regulated problem-solving and goal setting skills. Remedial and Special Education. doi:10. 1177/07419325030240020601.

Pinder-Amaker, S. (2014). Identifying the unmet needs of college students on the autism spectrum. Harvard Review of Psychiatry. doi:10. 1097/HRP.0000000000000032.

*Skinner, C. H., Bamberg, H. W., Smith, E. S., \& Powell, S. S. (1993). Cognitive cover, copy, and compare: subvocal responding to increase rates of accurate division responding. Remedial and Special Education. doi:10.1177/074193259301400107.
Southall, C. M., \& Gast, D. L. (2011). Self-management procedures: a comparison across the autism spectrum. Education and Training in Autism and Developmental Disabilities, 46, 155-171.

* Srikameswaran, S., \& Martin, G. L. (1984). A component analysis of a self-management program for improving work rates of mentally handicapped persons. The Mental Retardation and Learning Disability Bulletin, 12, 39-52.

Stokes, T. F., \& Baer, D. M. (1977). An implicit technology of generalization. Journal of Applied Behavior Analysis. doi:10.1901/jaba. 1977.10-349.

Super, D. E. (1983). Assessment in career guidance: toward truly developmental counseling. The Personnel and Guidance Journal. doi:10. 1111/j-2164-4918.1983.tb0009.x.

*Todd, T., Reid, G., \& Butler-Kisber, L. (2010). Cycling for students with ASD: self-regulation promotes sustained physical activity. Adapted Physical Activity Quarterly, 27, 226-41.

*Tollefson, N., Tracy, D. B., Johnsen, E. P., \& Chatman, J. (1986). Teaching learning disabled students goal-implementation skills. Psychology in the Schools. doi:10.1002/1520-6807(198604) 23:2<194::AID-PITS2310230213>3.0.CO;2-C

*Trammel, D. L., Schloss, P. J., \& Alper, S. (1994). Using self-recording, evaluation, and graphing to increase completion of homework assignments. Journal of Learning Disabilities. doi:10.1177/ 002221949402700202

VanBergeijk, E., Klin, A., \& Volkmar, F. (2008). Supporting more able students on the autism spectrum: college and beyond. Journal of Autism and Developmental Disabilities. doi:10.1007/s10803-0070524-8.

*Wanlin, C. M., Hrycaiko, D. W., Martin, G. L., \& Mahon, M. (1997). The effects of a goal-setting package on the performance of speed skaters. Journal of Applied Sport Psychology. doi:10.1080/ 10413209708406483.

*Ward, P., Crouch, D. W., \& Patrick, C. A. (1998). Effects of peermediated accountability on opportunities to respond and correct skill performance by elementary school children in physical education. Journal of Behavioral Education. doi:10.1023/a:1022868808642

*Winn, B. D., Skinner, C. H., Allin, J. D., \& Hawkins, J. A. (2004). Practicing school consultants can empirically validate interventions. Journal of Applied School Psychology. doi:10.1300/J370v20n02_07 